\title{
浅谈海绵城市建设的特征及其措施
}

\author{
呼苗 ${ }^{1}$ 王立文 ${ }^{2}$
}

1 富平县城乡规划管理局 2 融创中国天津区域西安公司

DOI:10.32629/btr.v1i4.1620

[摘 要] 海绵城市建设目的是使城市生态环境全方位得到改善, 随着低碳环保概念的深入, 各国环保意识不断增强, 海绵城市 建设非常重要。因此为了充分发挥海绵城市的作用, 本文阐述了海绵城市建设的意义及其要求,对海绵城市建设的主要特征及 其措施进行了论述分析。

[关键词] 海绵城市建设; 特征; 要求; 措施

城市开发建设的进程中, 严重的硬质化, 将原本可以大 量渗入地下的雨水在短时间内形成径流, 经地下管网快速 排放, 排水系统在不堪重负的情况下发生内涝, 并将地表以 及沉积在地下雨污管网的污染物, 在短时间内会突发性冲 刷汇入自然水系, 引发水体污染。同时, 由于雨水受到硬质 地面的阻隔, 无法渗透到地下, 地下水长时间得不到补充, 导致地下水位逐年下降, 河流干涸, 生物陨灭, 生态环境受 到严重的破坏。中国大部分城市普遍存在逢雨必涝、水生 态恶化、水资源紧缺、水环境污染、水安全缺乏保障等一 系列问题。建设海绵城市是解决这一系列问题的重要出路。 习近平总书记曾说, 我们要建设自然积存、自然渗透、自然 净化的 “海绵城市”。海绵城市就是为解决这一系列问题而 提出的, 以下对海绵城市的主要意义、特征及其措施进行了 探讨分析。

\section{1 海绵城市建设的意义及其要求分析}

1.1 海绵城市建设的重要意义

主要表现为: (1) 生态意义。在城市规划建设中海绵城 市这一理念的引入调整了城市中生态系统, 提高环境质量, 绿地增多, 硬化路面减少, 合理的处理雨水, 甚至将雨水回收 处理, 应用于工业的生产。不但可以带来经济利润, 还改善了 生态环境。(2) 社会意义。第一, 为老旧城区海绵城市规划设 计提供了新思路。相比建设大型地下调蓄池、大规模改造雨 水管线等方案, 改造设置一些城市 “海绵体” 是一个更加可 行的思路。比如城市道路可结合道路绿化带、树池等绿化空 间, 布置生态树池、植草沟等低影响开发设施, 采用“渗、滞、 蓄、净、用、排” 等措施, 有效地对地表径雨水加以引导利 用。第二、海绵城市规划设计可以减少城市内涝的发生。通 过海绵城市的建设, 将 “渗、滞、蓄、净、用、排” 等措施 与城市建设合理地结合起来, 大大减轻城市防洪排涝的压力, 有利于减少城市洪涝灾害的发生, 维护城市居民安定的生活 环境。(3) 经济意义。海绵城市的规划建设需要与城市工程 管网以及城市景观设计相结合, 从而美化环境, 保护水资源, 节省治理水污染的费用。

1.2 海绵城市建设的要求

主要表现为:（1）创新要求。传统城市路面建设基本以
硬化路面为主, 而城市中的排水建设仅仅依靠排水管道, 虽 然在建设的初期取得一定的效果, 但随着城市的发展, 硬质 地面的增加, 强降雨短时间冲刷地表会造成城市洪涝现象, 因此在注重城市发展的同时, 引入海绵城市的建设理念。利 用透水材料、雨水花园、生态植草沟等设施, 减缓雨水的流 速, 让雨水慢下来。这种措施主要是在源头控制雨水, 将原本 雨量集中的源头变为分散, 通过调节源头对雨水进行净化, 甚至是回收一部分的雨水再重新的利用, 最终使雨水排放的 速度放缓, 减少城市灾害。(2)生态要求。第一、将城市建设 中的影响降到最低, 海绵城市的建设目的将能将强降雨对城 市带来的灾害影响降到最低, 从源头上解决问题, 用低影响 换来高收益。主要的措施是: 在海绵城市设计中, 保护湿地、 河流, 限制开发, 避免进一步造成破坏。对已经被破坏的, 可 以通过生态手段进行修护, 使当地的水能够正常的循环, 对 于一些严重缺水的地区, 可以利用人工调蓄, 补给地下水。第 二、加强生态系统的保护。海绵城市建设要求对城市生态环 境进行合理的开发保护。

\section{2 海绵城市建设的主要特征}

海绵城市建设的特征主要表现为:（1）协调性特征。主 要表现为城镇建设和生态环境关系的协调性方面。海绵城市 建设在开发地下水、自来水收集存储和排放过程中, 不只单 纯地凭借地下管道, 而是利用城市自然环境综合系统, 完成 各类水资源包括大气降水和地下水的吸收、存储任务, 进一 步使城市洪涝隐患得以遏制。(2) 弹性适应的特征。主要表 现为城市能够针对各类环境变化和自然灾害能够弹性适应。 海绵城市建设不仅在于城市内部水系统的恢复与循环, 同时 对于自然生态系统保护工作亦非常重要, 即强调城市系统的 自我调节可靠性。(3)转变传统排水防涝模式的特征。海绵 城市主张将以往快排式等排水方法予以摒弃, 将 “渗、滞、 蓄、净、用、排” 等措施贯穿于城市排涝工程始终。另外, 竭尽全力地将城市开发前后的水文特征保持不变, 加快城市 内部良性水循环系统的构建。

\section{3 加强海绵城市建设的措施}

3.1 蓄水措施

要求全面性保护并修复城市内部既有的排水系统, 将城 
市自身的一切实际情况考虑进去, 快速构筑起完善的雨水收 集、存储、调蓄等体系, 通过灵活化调节雨水时空分布等途 径, 保证雨水资源的科学性回收和重复性开发使用。针对城 市既有的河流、湖泊、湿地等区域实施防护, 制定健全的城 市内部河道整治、岸线保护等为主题的有关法规条例, 令已 然遭受冲击的水生态环境得到适当地修复, 并且借助通淤截 污、人工湿地构建、生态岸线等途径, 加以逐层调试。之后, 借助地下空间或是蓄水池等模式, 完成雨水调蓄设施的设置, 保证雨水加以妥善化地存储和调节应用, 进一步迎合现代我 国城市雨水可持续开发应用的理念。

\section{2 滞水措施}

海绵城市建设的滞水目的是放缓雨水汇集速度引流至 特定范围内, 常见控制模式包括下凹式绿地、植草生态沟、 雨水花园等。首先, 在坚向设计环节中, 要尽量使绿地、公园 等区域低于地面, 并采用下沉式绿地或道牙开口等方式, 将 雨水引流至绿地中滞留, 为后续雨水溢流与周边自然区域引 流等目标逐层贯通奠定基础。其次, 生态植草沟即植被覆盖 的排水渠, 对于暴雨径流疏散工作有着极为高效的引流价值, 植草沟的结构将细化为植被、种植土、过滤层, 渗排水管和 砾石层, 特定的排水结构可以将各类污染物过滤并改善水 质。和以往地下管布置方式相比, 植草沟建设和养护工序流 程所消耗的成本, 整体上要优越一些, 同时还可以将乡土植 被加以协调利用, 营造出地方特色的景观空间、提升区域生 物的多样性, 最终为生物提供越来越多的栖息空间。

3.3 渗水措施。海绵城市建设的渗水措施需要透过下垫 面来收集雨水, 如透过道路、绿地等可渗水面, 其中最为常见 的有屋顶绿化和可渗透地面铺装等。屋顶绿化的结构细化为 栽培基层、过滤层、排水系统、防根穿刺层、绝缘层、防水 层等, 将雨水过滤引流至雨水收集系统, 同时可以改善气候 并且美化城市景观。而在进行城市路面等区域规划改建环节 中, 要求改良设计传统硬质铺装方案, 如沿用渗透性良好的 硬质铺装结构, 在所属区域环境绿化理念指导作用下, 针对 雨水予以科学性地吸纳, 规避地下水回灌问题重复滋生, 令 雨水经过合理程度地渗透和滞留之后, 发挥出更为理想的减 洪、水质净化和地下水涵养的功能特性。

\section{4 净水措施}

海绵城市建设的净水主要是借助污水与河道治理、土壤 和湿地净化等方式, 进行雨水净化的过程。土壤渗滤净化和
雨水收集工作可以同时进行, 其中吸纳整合的雨水会透过穿 孔管向净化池或是贮存的渗滤地排入, 并且在顺利地完成渗 滤净化任务后, 其余雨水则会因为地表流速过快或是土壤渗 透达到饱和状态等, 而难以借助土壤表层完成净化工作, 需 要额外配合地表的水生植物等手段加以过滤处理, 之后再向 初级净化池排入。归结来讲, 人工湿地在进行雨水净化管理 环节中可以细化为两道工序, 包括初级净化池和次级净化池, 其中前者主要是针对未经土壤渗滤的雨水加以净化处理, 而 次级净化池则是将初级净化池排出的雨水或是土壤渗滤排 出的雨水进行持续净化控制。经过上述工序流程处理的雨水, 水质明显得到前所未有的改善, 完全可以考虑将其向下游排 水池中加以排入, 结合人工方式, 如水百等将二次净化的雨 水吸纳到山地的拒水池之中, 其间水洜还承担着一类重要使 命, 就是进行初级和次级净化池、次级净化池和清水池之间 的循环净化控制。

\section{5 排水用水措施}

海绵城市建设的排水要求通过 “渗、滞、蓄、净” 等措 施后, 再借助城市坚向设计、人工排水设施、天然排水模式 等手段交叉使用, 完成雨水排放任务的过程。通常沿用自然 排水方式, 与海绵城市排水系统相结合。在整个过程中我们 将雨水引流至 “蓄” 水池, 通过净化处理, 这些 “净” 化后的 雨水可以直接作为城市中水, 用来市政酒水、洗车、灌溉、 搅拌混凝土等。最后, 那些多出来的短时间内无法利用的雨 水才会通过溢水管排放至市政雨水管网, 给城市管网成功 “解压”。

\section{4 结束语}

综上所述, 随着城市化建设的不断推进以及洪涝灾害和 水资源短缺问题的日益严重, 导致环境失衡日益加剧, 使得 建立完整有效的水安全治理系统非常重要。而科学合理的海 绵城市建设可以合理解决这一问题, 因此对海绵城市建设的 特征及其措施进行分析具有重要意义。

\section{[参考文献]}

[1]鞠茂森.关于海绵城市建设理念、技术和政策问题的 思考 [J].水利发展研究,2015,15(03):7-10.

[2]崔维强.基于海绵城市理念的城市规划方法[J].现代 园艺,2016,(12):149.

[3]万之瑛.海绵城市建设理念、技术和政策问题的思考 [J].中华建设,2016,(05):68-69. 